\title{
Intoxicação natural por Cestrum intermedium em bovinos no Rio Grande do Sul, Brasil
}

\author{
Spontaneous poisoning by Cestrum intermedium in cattle in Rio Grande do Sul, Brazil \\ Paulo Mota Bandarra ${ }^{\mathrm{I}}$ Pedro Soares Bezerra Júnior ${ }^{\mathrm{I}}$ André Mendes Ribeiro Corrêa ${ }^{\mathrm{I}}$

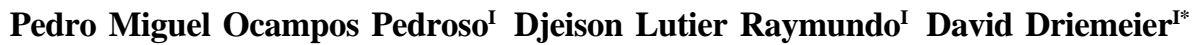

- NOTA-

\section{RESUMO}

Em junho de 2007, uma mortalidade de bovinos com sinais clínicos e lesões de insuficiência hepática aguda em uma propriedade, na região da encosta da serra do Rio Grande do Sul, foi atribuída ao consumo de Cestrum intermedium. De um total de 17 bovinos, dois morreram com curso clínico inferior a 12 horas, apresentando tremores musculares, andar cambaleante, reações agressivas, decúbito lateral e morte. À necropsia, o fígado estava moderadamente aumentado de volume e com acentuação do padrão lobular. Histologicamente, o fígado apresentava necrose de coagulação centrolobular, difusa, aguda e acentuada. As alterações patológicas associadas à presença e a evidência de consumo da planta pelos bovinos permitiram o diagnóstico.

Palavras-chave: Cestrum intermedium, intoxicação por planta, hepatotoxicose aguda, necrose hepática, bovinos.

\section{ABSTRACT}

In June of 2007, mortality in cattle with clinical signs and lesions of acute hepatic insufficiency on a farm located in the hillside of Rio Grande do Sul mountain range was attributed to Cestrum intermedium consumption. From 17 bovines, two died up to 12 hours presenting clinical signs such as muscular tremors, incoordination, aggressiveness, lateral recumbence and death. Macroscopic lesions were found primary in the liver and were characterized by a slightly increased volume and diffuse accentuation of the lobules. Microscopically, the liver showed diffuse and accentuated centrilobular coagulative necrosis. The presence of Cestrum intermedium plants that was being ingested by the bovine associated with the hepatic lesions was decisive for the diagnosis.
Key words: Cestrum intermedium, plant poisoning, acute hepatotoxicosis, liver necrosis, cattle.

Cestrum intermedium é uma árvore da família Solanacea, conhecida popularmente como “mata-boi”, “coerana”, "piloteira preta” e "erva de tinta”. A planta atinge três a quatro metros de altura, possui inflorescências branco-amareladas e fruto preto (GAVA, 1993; GAVA et al., 1996). Ela é encontrada em terras férteis e úmidas, principalmente capoeiras, campos abandonados e beira de cercas e estradas (TOKARNIA et al., 2000). O Cestrum intermedium é tido como planta tóxica de maior importância no extremo Oeste e Noroeste de Santa Catarina e Sudoeste do Paraná (GAVA, 1993). A intoxicação por esta planta causa um quadro clínico-patológico característico de insuficiência hepática aguda. O curso clínico da doença varia de 12 a 72 horas e se caracteriza por perda do apetite, atonia ruminal, andar lento com os membros afastados, sendo que alguns animais podem apresentar agressividade, decúbito esternal, gemidos e decúbito lateral com movimentos de pedalagem, salivação e morte (GAVA, 1993; GAVA et al., 1996; TOKARNIA et al., 2000). A planta é experimentalmente tóxica para bovinos em doses únicas superiores a $25 \mathrm{~g} \mathrm{~kg}^{-1}$ e é mais facilmente ingerida pelos bovinos quando cortada e deixada no local até sofrer desidratação (GAVA et al., 1996). A principal lesão macroscópica é observada no

ISetor de Patologia Veterinária, Universidade Federal do Rio Grande do Sul (SPV-UFRGS). Av. Bento Gonçalves, 9090, Agronomia, 91540-000, Porto Alegre, RS, Brasil. E-mail: davetpat@ufrgs.br. *Autor para correspondência. 
fígado e caracteriza-se pela acentuação do padrão lobular. Outras lesões macroscópicas freqüentemente encontradas são: ressecamento do conteúdo do omaso, cólon e do reto, sendo as fezes envolvidas por muco e estrias de sangue e hemorragias em diversos órgãos, incluindo tecido subcutâneo, endocárdio, epicárdio e outras superfícies serosas. Histologicamente, a lesão hepática se caracteriza por necrose de coagulação dos hepatócitos nas regiões centrolobular e intermediária associada à intensa congestão e à degeneração vacuolar dos hepatócitos na periferia da necrose (GAVA et al., 1996).

No mês de junho de 2007, uma fêmea bovina de 18 meses, raça indefinida, foi necropsiada pelo Setor de Patologia Veterinária da Universidade Federal do Rio Grande do Sul (SPV-UFRGS) em uma propriedade rural, no município de Nova Petrópolis, onde morreram dois bovinos que haviam apresentado um curso clínico agudo. Durante a necropsia, fragmentos de diversos órgãos foram coletados, fixados em formalina tamponada a $10 \%$, posteriormente processados conforme métodos histológicos convencionais e corados pela hematoxilina e eosina. O histórico da propriedade e os dados clínicos e epidemiológicos foram obtidos com o médico veterinário requisitante, o proprietário do estabelecimento e por meio de observações em visita à propriedade.

De um total de 17 bovinos, dois (12\%) morreram em um intervalo de dois dias apresentando um curso clínico de 6-12 horas caracterizado por tremores musculares, andar cambaleante, reações agressivas, com posterior decúbito lateral e morte. Os animais eram mantidos em um piquete de aproximadamente 1,7 hectares de campo nativo, recebiam silagem de milho em um cocho único e não recebiam suplementação mineral. No piquete onde os animais eram mantidos, havia exemplares de Cestrum intermedium (Figura 1a) apresentando sinais claros de terem sido consumidas. O consumo da planta pelos animais também foi observado no momento da visita à propriedade (Figura 1b). A planta foi identificada no Departamento de Botânica da UFRGS.

O bovino necropsiado apresentava mucosas oculares e vaginal pálidas, retração do globo ocular, evidenciando desidratação e fezes secas envolvidas por muco e sangue. Petéquias, equimoses e sufusões foram encontradas no tecido subcutâneo do pescoço, da região temporal, da região axilar, no epicárdio, no endocárdio, no timo, na tireóide, na superfície serosa do rúmen, no omento e no mesentério. O fígado estava moderadamente aumentado de volume, com bordos arredondados e havia notável acentuação do padrão lobular na superfície subcapsular e de corte, caracterizada por áreas vermelho-escuras centrolobulares intercaladas com áreas vermelho-claras periféricas (Figura 1c). A vesícula biliar estava repleta e com edema gelatinoso e translúcido da parede. No rúmen, no omaso e no cólon, o conteúdo estava ressecado. No reto, havia fezes ressequidas recobertas por muco e estrias de sangue. Histologicamente a lesão mais importante era encontrada no fígado e caracterizava-se por necrose de coagulação, centrolobular, difusa e acentuada, caracterizada por aumento da eosinofilia citoplasmática, picnose, cariorrexia e cariólise associadas à congestão e à hemorragia. Adicionalmente, havia acentuada tumefação e vacuolização de hepatócitos, por vezes acompanhadas de picnose na zona intermediária e, em menor grau, na zona periportal (Figura 1d). Nas áreas de necrose, espaço porta e no lúmen de alguns ductos biliares foi observada discreta infiltração de neutrófilos e macrófagos. No coração, havia hemorragia subendocárdica e subepicárdica. No timo e na tireóide, foram encontradas congestão e hemorragia difusa moderada e no baço foi encontrada hemossiderose difusa moderada.

O diagnóstico da intoxicação foi estabelecido pelas lesões macroscópicas e histológicas e pela presença da planta na propriedade com sinais de consumo. Isso foi confirmado pelo pronto consumo da mesma pelos animais durante a visita à propriedade. Provavelmente, a baixa disponibilidade de pastagem e a escassa suplementação nutricional para os animais associadas à superlotação contribuíram para o consumo da planta pelos animais.

Necrose e degeneração de hepatócitos da região centrolobular são particularmente comuns em doenças hepatotóxicas. Isso se deve principalmente à grande atividade enzimática das oxidases de função mista que estão presentes em maior quantidade nos hepatócitos desta região. Estas enzimas são capazes de transformar compostos exógenos inativos em metabólitos tóxicos (CULLEN, 2007). Os sinais clínicos neurológicos da encefalopatia hepática provavelmente resultam de acúmulo na corrente sangüínea, no líquido cefalorraquidiano e no encéfalo de substâncias como a amônia, os ácidos graxos de cadeias curtas e mercaptanos, além de alterações nas concentrações de neurotransmissores e glicose (KELLERMAN et al, 2005).

O quadro clínico-patológico verificado neste caso é semelhante ao causado por outros agentes hepatotóxicos agudos. Como diagnóstico diferencial da intoxicação por Cestrum intermedium no Rio Grande do Sul, devem ser consideradas outras causas tóxicas de necrose hepática aguda previamente 


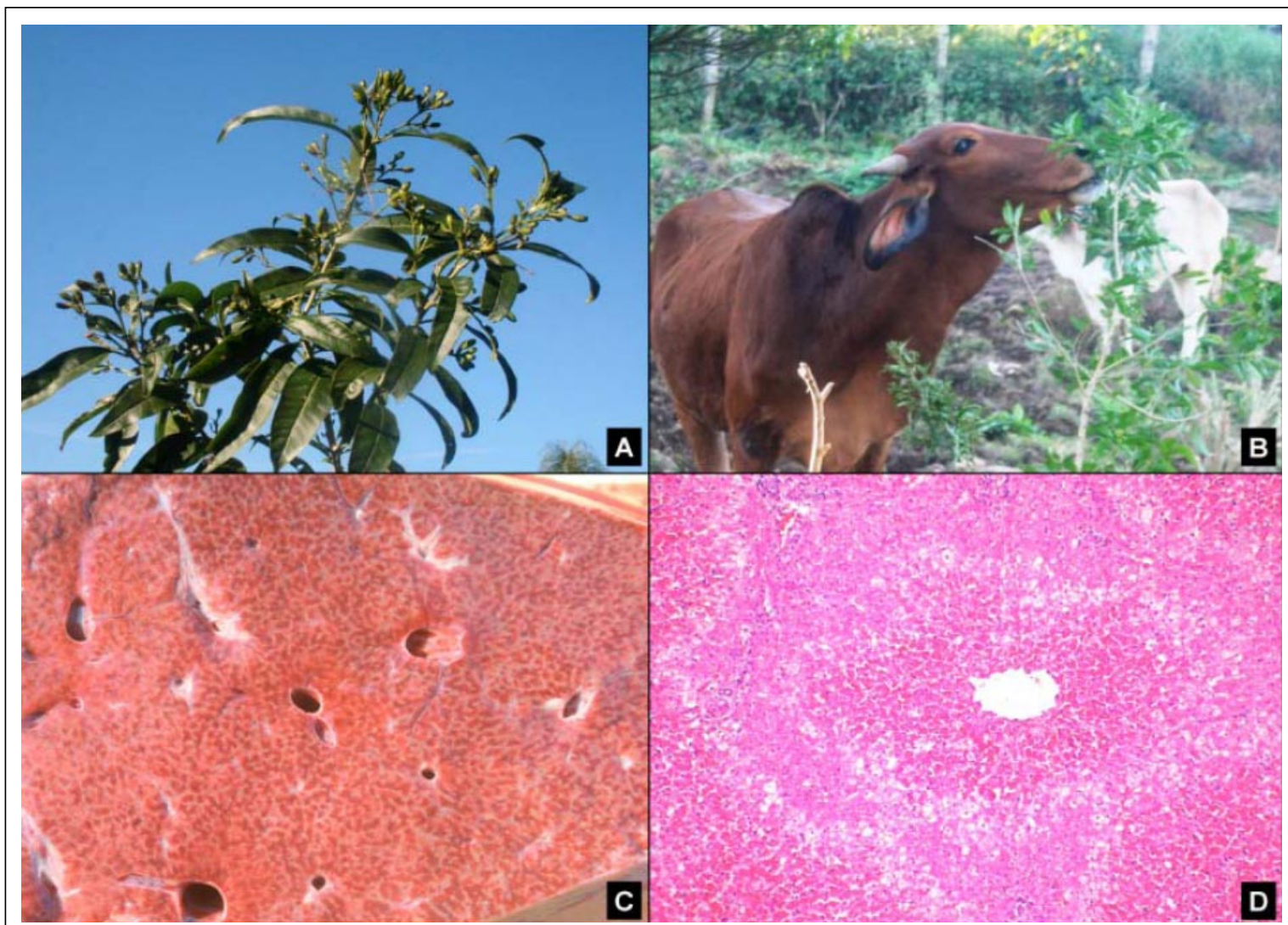

Figura 1 - Intoxicação natural em bovinos por Cestrum intermedium. A. Aspecto das folhas e dos frutos de Cestrum intermedium (Solanaceae) da propriedade. B. Bovino consumindo a planta espontaneamente na propriedade. C. Superfície de corte do fígado apresentando acentuação do padrão lobular, em que são observadas áreas centrolobulares vermelho-escuras circundadas por áreas claras. D. Fotomicrografia da figura C. Necrose de coagulação centrolobular acentuada, associada à vacuolização de hepatócitos na zona intermediária. HE. Obj. 10.

descritas em ruminantes neste Estado, como intoxicação por Dodonea viscosa (COLODEL et al., 2003), Trema micrantha (TRAVERSO et al., 2003), Xanthium cavallinesii (MÉNDEZ et al., 1998), Cestrum parqui (RIET-CORREA et al., 1986), Myoporum laetum (RAPOSO et al., 1998) e Perreyia flavipes (RAYMUNDO et al., 2008). Em outros Estados do Brasil ainda são descritos outros agentes que causam necrose hepática aguda em ruminantes, como Cestrum corymbosum (GAVA et al., 1991), Cestrum laevigatum (PEIXOTO et al., 2000), Vernonia mollissima (DÖBEREINER et al., 1976), Vernonia rubricaulis (TOKARNIA \& DÖBEREINER, 1982), Sessea brasiliensis (CANELLA et al., 1968) e Crotalaria retusa (NOBRE et al., 2005). Intoxicação por closantel também deve ser considerada no diagnóstico diferencial por apresentar necrose hepática centrolobular (ECCO et al. 2006).

Os dados do presente relato indicam que a planta deve ser também considerada em casos de hepatopatia tóxica aguda em bovinos no Rio Grande do Sul. Apesar de Cestrum intermedium ser considerada a planta tóxica de maior importância para bovinos no extremo Oeste e Noroeste de Santa Catarina e Sudoeste do Paraná (GAVA, 1993), sua importância entre as demais causas hepatotóxicas descritas no Rio Grande do Sul ainda precisa ser determinada.

\section{REFERÊNCIAS}

CANELLA, C.F.C. et al. Intoxicação por Sessea brasiliensis Toledo em bovinos. Pesquisa Agropecuária Brasileira. v.3, p.333-340, 1968.

COLODEL, E.M. et al. Spontaneous poisoning by Dodonea viscosa (Salpindaceae) in cattle. Veterinary and Human Toxicology, v.45, n.3, p.147-148, 2003.

CULLEN, J.M. Liver, biliary system and exocrine pancreas. In: MCGAVIN, M.D.; ZACHARY, J.F. Pathologic basis of veterinary disease. St. Louis: Mosby, 2007. p.393-461.

DÖBEREINER, et al. Vernonia mollissima, planta tóxica responsável por mortandades de bovinos no sul de Mato Grosso. Pesquisa Agropecuária Brasileira, v.11, p.49-58, 1976.

Ciência Rural, v.39, n.1, jan-fev, 2009. 
ECCO, R. et al. Closantel toxicosis in kid goats. Veterinary Record, v.159, n.17, p.564-566, 2006.

GAVA, A. et al. Intoxicação por Cestrum corymbosum var. hirsutum (Solanaceae) em bovinos no estado de Santa Catarina. Pesquisa Veterinária Brasileira, v.11, n.3/4, p.71-74, 1991.

GAVA, A. Intoxicação por Cestrum intermedium. In: RIETCORREA, F. et al. Intoxicações por plantas e micotoxicoses em animais domésticos. Pelotas: Hemisfério sul, 1993. Cap.3, p.72-74.

GAVA, A. et al. Intoxicação por Cestrum intermedium (Solanaceae) em bovinos. Pesquisa Veterinária Brasileira, v.16, n.4, p.117-120, 1996.

KELLERMAN, T.S. et al. Liver. In: Plant poisonings and mycotoxicosis of livestock in Southern Africa. 2.ed. Cape Town: Oxford University, 2005. Cap. 1, p.3-62.

MÉNDEZ, M.C. et al. Intoxication by Xanthium cavanillesii in cattle and sheep in Southern Brazil, Veterinary and Human Toxicology, v.40, n.3, p.144-147, 1998.

NOBRE, V.M.T. et al. Acute intoxication by Crotalaria retusa in sheep. Toxicon, v.45, n.3, p.347-352, 2005.
PEIXOTO, P.V. et al. Cestrum laevigatum poisoning in goats in southeastern Brazil. Veterinary and Human Toxicology, v.42, n.1, p.13-14, 2000.

RAPOSO, J.B. et al. Experimental intoxication by Myoporum laetum in cattle. Veterinary and Human Toxicology, v.40, n.5, p.275-277, 1998.

RAYMUNDO, D.L. et al. Spontaneous poisoning by larvae of Perreyia flavipes (Pergidae) in sheep. Pesquisa Veterinária Brasileira, v.40, n.1, p.19-22, 2008.

RIET-CORREA, F. et al. Intoxicação por Cestrum parqui (Solanaceae) em bovinos no Rio Grande do Sul. Pesquisa Veterinária Brasileira, v.6, n.4, p.111-115, 1986.

TOKARNIA, C.H. et al. Plantas hepatotóxicas. In Plantas tóxicas do Brasil. Rio de Janeiro: Helianthus, 2000 p. 80-110.

TOKARNIA, C.H.; DÖBEREINER, J. Intoxicação de bovinos por Vernonia rubricaulis (Compositae) em Mato Grosso. Pesquisa Veterinária Brasileira. v.2, n.4, p.143-147, 1982.

TRAVERSO, S.D. et al. Intoxicação natural por Trema micrantha em caprinos. Ciência Rural, v.33, n.1, p.133136, 2003 